\title{
A spherical near-field antenna test facility
}

\author{
Hansen, Jesper; Larsen, Flemming Holm
}

Published in:

Antennas and Propagation Society International Symposium,

Publication date:

1980

Document Version

Publisher's PDF, also known as Version of record

Link back to DTU Orbit

Citation (APA):

Hansen, J., \& Larsen, F. H. (1980). A spherical near-field antenna test facility. In Antennas and Propagation Society International Symposium, (pp. 264-267). IEEE.

\section{General rights}

Copyright and moral rights for the publications made accessible in the public portal are retained by the authors and/or other copyright owners and it is a condition of accessing publications that users recognise and abide by the legal requirements associated with these rights.

- Users may download and print one copy of any publication from the public portal for the purpose of private study or research.

- You may not further distribute the material or use it for any profit-making activity or commercial gain

- You may freely distribute the URL identifying the publication in the public portal

If you believe that this document breaches copyright please contact us providing details, and we will remove access to the work immediately and investigate your claim 
A SPHERICAL NEAR-FIELD ANTENNA TEST FACILITY

\author{
Jesper E. Hansen and Flemming Holm Larsen \\ Electromagnetics Institute \\ Technical University of Denmark \\ DK-2800 Iyngby, Denmark
}

For future testing of spacecraft antennas a spherical near-field scanning facility has been developed by the Technical University of Denmark in cooperation with the European Space Agency (ESA) (ref. I).

Spherical near-field testing has a at least two advantages over other nearfield schemes. The mechanical scanning in the spherical coordinates $\theta$ and $\phi$ can very simply be done using standard equipment present in most anechoic chambers, and the far field is obtained in all directions of space. Thus, an absolute calibration of the probe is not needed for the measurement of directivity. As a drawback of spherical near-field testing, mathematical complexity has been mentioned. With the development of the near-field to far-field transformation program SNIFTC complexity is no longer a problem.

One of the main advantages of the spherical scanning system is the fact that it can readily be implemented using standard antenna positioning equipment designed for far-field measurements. In the present facility an antenna tower type 5871 A from Scientific-Atlanta is used for rotation of the antenna to be measured (the test antenna) about a horizontal axis. For rotation about the intersecting vertical axis a standard azimuth-positioner could have been used. However, for various reasons a special azimuth positioner was designed for the present facility.

The measuring antenna (probe) is mounted in a fixed, horizontal position with its axis pointing towards the intersection of the horizontal and vertical axes of the antenna tower. The probe is mounted on an absorber-clad probe tower which can be moved back and forth on rails. In this way the radius of the spherical surface on which the test antenna near-field is probed can be varied (fig. 1). The facility is implemented at the TuD anechoic chamber.

The facility makes use of a scientific-Atlanta model 1774 phase amplitude receiver and a signal source of high stability. The system is a dual channel system permitting simultaneous measurement of two orthogonal polarizations of the test antenna. The probe antenna is a conical horn with a gain of $15 \mathrm{~dB}$ at $11.8 \mathrm{GHz}$. With two channels the measurement time is cut almost by $50 \%$. In addition, measurement of the two polarizations are made in precisely the same points without the need for mechanical rotation of the probe (ref. 2).

Data collecting and controlling is microprocessor based. The microcomputer triggers and reads data from the phase and amplitude displays of the receiver. It also controls the positioning of the test antenna in $\theta$ and $\phi$. Data is stored on magnetic tape for later processing on an IBM 3033 computer. The data processing is done in two FORTRAN packages, SNIFTC for near-field to far-field transformations, and FACSIM for simulation of the influence of

\title{
*
}

ESTEC Contract No. 3337/77/NL/AK.

$$
\text { CH1557-8/80/0000-0264\$00.75 (C) } 1980 \text { IEEE }
$$


As input data SNIFTC uses the signal from the probe antenna ("input probe") and calculates the far field taking probe directivity into account. Both the near field and the computed far field are described in points equispaced in $\theta$ and $\phi$ of the spherical coordinate system $r \theta \phi$. SNIFTC may also be used to compute the field at a spherical surface with finite radius.

Formally, the output field is calculated as the signal that would be received by some measuring antenna ("output probe") located in the far field or at any other distance where the field is wanted.

SNIFTC is based on the formula for the signal $W$ received by the probe antenna

$$
\begin{aligned}
W(A, \phi, \theta, X) & =\sum_{s m n \mu} Q_{s m n} e^{i m \phi} \dot{C}_{\mu m}^{n}(\theta) e^{i \mu X} P_{s \mu n}(A) \\
P_{s \mu n}(A) & =\frac{I}{2} \sum_{\sigma \nu} C_{\sigma \mu \nu}^{s n}(A) P_{\sigma \mu \nu}
\end{aligned}
$$

In this formula, the $Q_{\text {smn }}$ are spherical wave coefficients of the field radiated by the test antenna with $s=1$ for TE waves and $s=2$ for TM waves. The rotation coefficients $e^{i m \phi} d_{\mu m}^{n}(\theta) e^{i \mu X}$ and the translation coefficients $\frac{1}{2} c_{\mathrm{\sigma H}}^{\mathrm{Sn}}(\mathrm{A})$ describe the coupling Exom modes with indices smn in the test antenna coordinate system to modes with indices $\sigma \mu \nu$ in the probe system.

The response of the probe to each incoming mode is described by the receiving coefficient $P_{\sigma \mu v}$. In spherical near-field measurements the signal $W(A, \phi, \theta, x)$ is measured in amplitude and phase on a full sphere with radius $A$ at points spaced equidistantly in $\theta$ and $\phi$, with two polarization orientations $x=0^{\circ}$ and $x=90^{\circ}$ applied in each point. From these data, the spherical wave coefficients $Q_{\mathrm{smn}}$ are computed and the far field is found by the equation with $A=\infty$ and a Hertzian dipole as output probe.

The efficiency and accuracy of SNIFTC has been studied by using a theoretical model (ref. 3). For an antenna with a diameter of 50 wavelength and sampling increments $\Delta \theta=\Delta \phi=1$ degree the far field was computed in 65160 points in less than three minutes c.p.u. time. The error was in all points more than $65 \mathrm{~dB}$ below the isotropic level.

The spherical near-field scanning facility described has been in operation since April 1979. Results from the first near-field measurements taken at two different distances on a $31 \mathrm{~dB}$ reflector antenna are shown in figure 2 and 3. The fact that two rather different near-fields (fig. 2) are transformed into virtually the same far fields (fig. 4) confirms the validity of the method and the accuracy of the facility.

Presently, the facility is being updated for automatic operation using an HPlOOO minicomputer for control. This computer will also be used for performing all data reduction and near-field to far-field transformations. 


\section{REFERENCES}

Ref. I H.Bach, E.Lintz Christensen, Jesper E.Hansen, Frank Jensen and F. Holm Larsen, "Facility design and test runs." Experimental spherical near-field antenna test facility. Final Report, Vol. I (summarY of work). ESA Contract No. 3337/NL/AK. Electromagnetics Institute, Technical University of Denmark, Report R208, April 1979.

Ref. 2 F.Holm Larsen and Jesper E.Hansen, "A dual-polarized probe system for near-field measurements." Int. IEEE AP-S Symp. Digest, pp 557-560, June 1979 .

Ref. 3 F.Jensen, "Computer simulations as a design tool in near-field testing." IEE Conference Publication No. 169, Part 1, pp 111-114, London, November 1978.

ReI. 4 F.Holm Larsen, "Improved algorithm for probe-corrected spherical near-field/far-field transformation." Electronics Letters, Vol. 15, No. 19, pp 588-590, September 1979 .

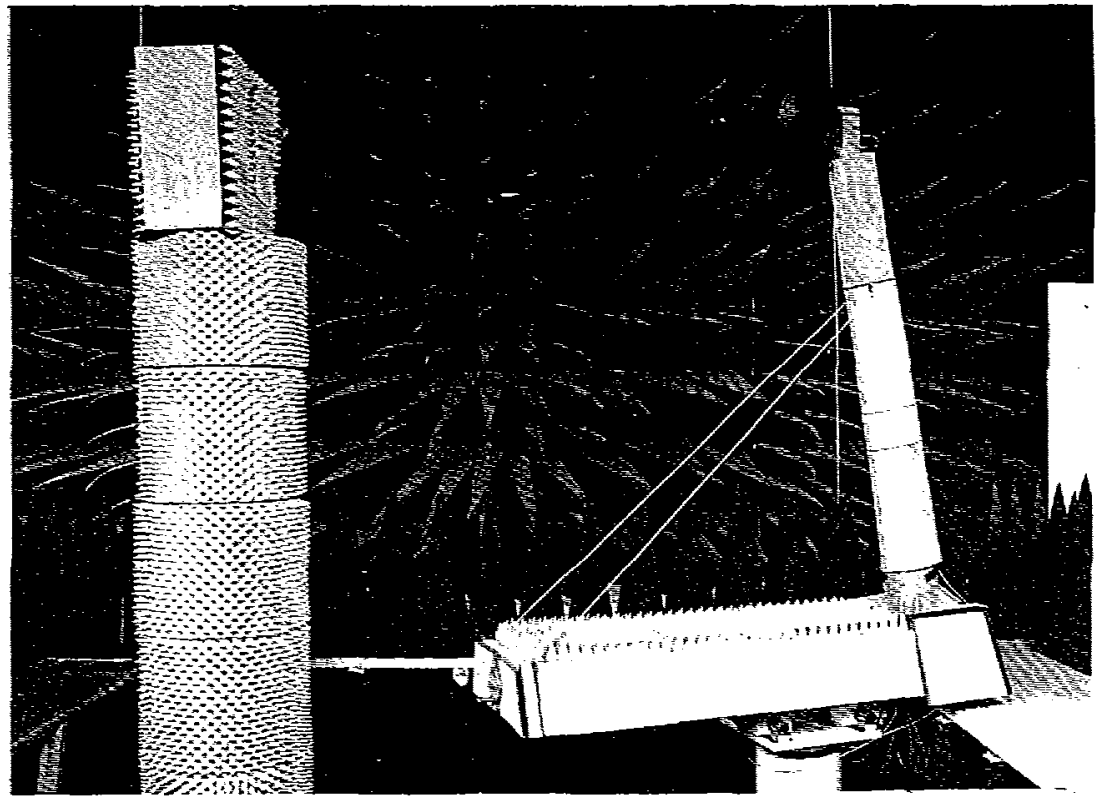

Fig. 1. Probe tower with dual polarized x-band probe at left can be moved on rails (not shown) to provide different radii of the measurement sphere. The measurement sphere is centered at the test antenna (OTS Euxobeam antenna) shown on the antenna positioner at right. 

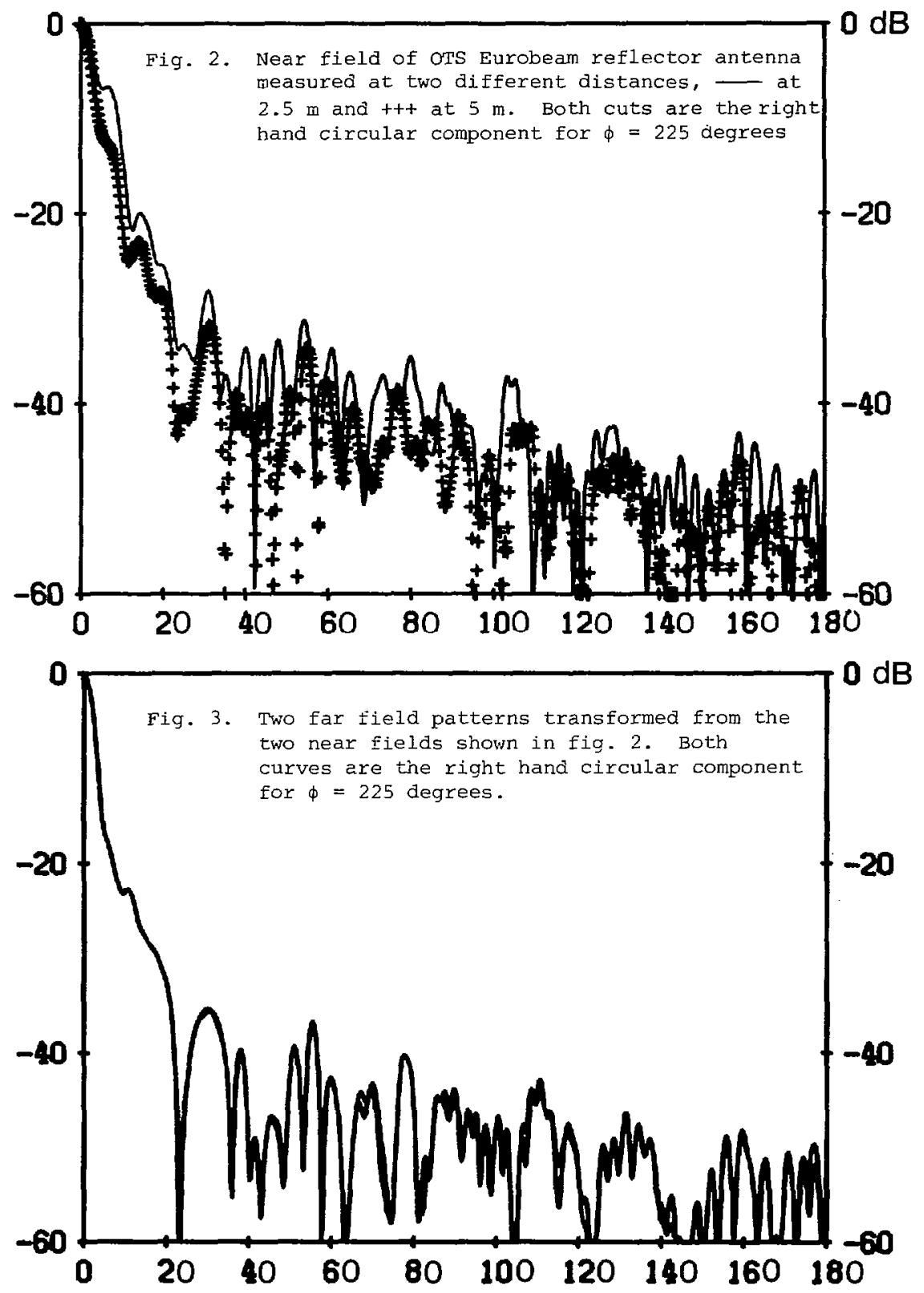

267 